\title{
Transformative learning theory and migration: Having transformative and edifying conversations
}

\author{
Saskia Eschenbacher
}

Akkon University of Applied Sciences Berlin, Germany (saskia.eschenbacher@akkonhochschule.de)

\begin{abstract}
This paper introduces the concept of transformative conversation inspired by Arcilla's concept of edifying conversation, as an extension of TL theory's notion of discourse, in the context of adult education and migration. By contrasting the idea of exchanging arguments with opening space for conversation and one's private quest for meaning and self-understanding, I introduce the idea of becoming a fellow transformative conversationalist as an appropriate attitude for promoting TL. I will (1) differentiate between an instrumental and a transformative notion of learning in the context of migration; (2) engage Rorty in a conversation with TL theory; (3) introduce Arcilla's concept of edifying conversation to join and broaden the ongoing conversation and develop the concept of transformative conversation.
\end{abstract}

Keywords: Edification; liberal learning; migration; transformative conversation; transformative learning

All of us impatient for sunrise, all of us in dread of it. All of us in search of home. (Khaled Hosseini, Sea Prayer)

\section{Introduction: In search for an attitude}

The experience of migration, the hope to find a new home, starts with leaving home, full of promise and threat. Migrants embark on perilous sea journeys - as in Sea Prayer (Hosseini) - or walk across continents. While the phenomenon of migration is wide and complex, the experience of migration is specific and individual. As a therapist, I have worked with migrant adults who fled to survive war. My training as a systemic therapist provides guidance - more precisely a useful attitude - for me working with survivors of 
violence and torture. I had to learn that I had no guidance for working with women who experienced war. I was in search of an attitude, an approach.

It is not only 'migration as a process of education and learning' (Kurantowicz, Salling Olesen, \& Wildemeersch, 2014, p. 146) that needs to be studied, but also how educators can find a way, an attitude, supporting migrants learning. 'For migrants learning is an inevitable part of life' (Morrice, 2014, p. 152). They need to cope with 'migratory grief' and transform 'a social stressful event' (Vinciguerra, 2017, p. 354) into an opportunity to learn and develop, or at least survive, while rebuilding a 'shattered life' (Magro \& Polyzoi, 2009 , p. 86). Migrants have to find a new home inside and outside of themselves, by reconstructing a life and identity (Morrice, 2013, Magro, 2009). The need to find new answers to the question of how to live, having been 'deprived abruptly and often quite violently of what was most meaningful in their lives' (Magro \& Polyzoi, 2009, p. 88), together with a loss of safety and self-understanding (ibid.), becomes a learning task. In what ways can adult educators support migrants on this journey of rebuilding and hopefully arriving in a new society, and a new, empowered self-understanding? How can hope and history rhyme?

Central to this learning process seems to be an understanding of the experience of migration, and how it puts one's life and self-understanding on hold; how it forces migrants to undergo processes of transformation without losing themselves while they have lost their way in the world. Is there any potential for learning, for (personal) growth and development in this adversity?

The theory of transformative learning (TL) (Mezirow, 1978) understands learning as an invitation to leave what one has taken for granted, maybe it is ones' self-understanding, or life as one knows it or one's assumptive clusters. This process can be traumatic. The theory of TL will be discussed later in this paper. Adult education offered under the umbrella of lifelong learning does not address trauma and personal narratives of flight if it is good education, it does, it indeed should], emerging out of the tension of looking to survive and realizing one's dreams. There is little space for mourning. At what cost is this deferred? How is this experienced? What stories are told or yet to be told?

The following question arises out of this search for an attitude that fosters learning transformatively: While searching for a home, is there a role for conversation about one's private quest for meaning? One where the role of an educator could be one of a fellow conversationalist engaged in transformative conversation, critically questioning takenfor-granted frames of reference, and turning that quest into an opportunity for transformation.

This paper introduces the concept of transformative conversation which is inspired by Arcilla's concept of edifying conversation (1995). This is an extension of TL's notion of discourse, in the context of adult education and migration. By contrasting the idea of exchanging arguments with opening a space for conversation and one's private quest for meaning and self-understanding, I introduce the idea of becoming a fellow transformative conversationalist as an appropriate attitude for promoting TL.

I will (1) differentiate between an instrumental and a transformative notion of learning in the context of migration. This is as backdrop for (2) bringing Rorty (1989) into a conversation with transformative learning theory, and (3) introduce Arcilla's concept of edifying conversation to join and broaden the ongoing conversation and develop the idea of transformative conversation. 


\section{Adult education in times of migration: Between instrumental learning and transformative learning}

There are answers to the question as to how adult education can support migrants in making their transition to the host country and becoming a member of society. Providing educational programmes is one way to help 'navigate complex paths, including perhaps improving their language skills and knowledge of local labour markets and cultures to ensure their sense of belonging and full participation in the host society' (Webb, Hodge, Holford, Milana, \& Waller, 2016, p. 213). These programmes often work under the assumption that migrants need to learn and be oriented into society and employment, whereas migrant's skills and resources are considered as 'non-resources' (Morrice, 2014, p. 157). Skills, resources and prior identities are less valued (Webb, 2017). This kind of informative, instrumental learning (e.g. learning a new language, and accommodating to a different culture) should be conducted in a respectful way towards the learners' cultural backgrounds (Wildemeersch, 2017). However, this need to learn and accommodate is intertwined with an identity of vulnerability and shame (Morrice, 2013). It operates from a deficit approach, an assumption that migrants are lacking something (knowledge, competences) that needs to be addressed, so that they can become included as citizens (e.g. Gibb, 2015, Morrice, 2014, 2019, Webb, 2015, Wildemeersch, 2017).

This is not surprising, as Morrice (2019) asserts that current western-centric framing reflects colonial logics and privileges, employing an assimilationist approach: 'Integration has become an identity issue with migrants having to prove their willingness to integrate by attending classes and passing tests' (Morrice, 2014, p. 156). Migrants are held responsible to demonstrate their willingness and ability to adapt (Morrice, 2019). It is this deficit approach (aiming for adaption and assimilation) from which adult education has to decouple and also liberate itself from post-colonial framings and search for a different framing (Morrice, 2019).

Wildemeersch (2017) proposes a more expansive idea of adult education in the context of migration and reflects on Biesta's (2012) distinction between three different pedagogical approaches. Wildemeersch (2017) advocates a pedagogy for publicness that sees the learner as an active participant within the public sphere, whereas the role of an educator is to challenge formerly unproblematic notions and ideas, employing a pedagogy of interruption. This approach is different from a pedagogy for the public. It operates under a deficit approach with huge overlap of what Morrice (2019) has criticized in the context of migration. It wants to reduce plurality by employing an assimilationist approach, where the educator is primarily an instructor. It is also different from a pedagogy of the public, where the educator is a facilitator, engaging in open-ended dialogue. The downside, however, is that the learner has to continuously engage in public issues in order to be considered a good citizen, while in the process it becomes private learning problems.

The pedagogy of interruption (Wildemeersch, 2017) is interesting, not only with regard to citizenship and adult education in general and in the context of migration, but also for expanding TL theory. It engages many of the same ideas, like interrupting and challenging taken-for-granted assumptions. His work allows us to depart from our current understanding of TL to shift our focus from trying to achieve a (tentative) consensus, which is seen as a given within TL theory (e.g. Mezirow, 1991). His work aims for dissensus, as it creates opportunities to engage in the public sphere. Wildemeersch introduces an element of dissensus as 'a sign of plurality, and this in turn refers to the fact that in our human condition, life choices are not predetermined but are open to the freedom of subjects to choose among the plurality of possibilities that the world offers' 
(2017, p. 119). This idea of the human condition, that one is not trapped by one way of looking at the world, is close to Rorty's (1989) idea of irony, as we will see later.

Wildemeersch (2017) introduces the idea of dissensus as a pedagogical approach that is highly relevant within the public sphere, from the perspective of citizenship education as a democratic practice and highlights

the need for a space of conversation, whereby participants and facilitators open spaces of conversation about the world they come from, and the world they want to live in. Such spaces of conversation are based on the principles of equity and respect for each other's uniqueness. Yet, it is also a practice that sometimes confronts us with the limits of our mutual understanding. (p. 114)

This conversation within the public sphere addresses the question: How do we want to live our lives? This paper adds to his notion of conversation by shifting the focus to another question that emerges for learners out of their migratory experiences: How do $I$ want to live $m y$ life? It invites the reader to shift the focus from mutual understanding to self-understanding. This process of learning holds the potential to become a transformative conversation within the private sphere, if one is able to rebuild a shattered life. This structural reorganization is central to Mezirow's notion of TL (Mezirow, 1978) and has to be the foundation for learning transformatively in the context of flight and migration.

\section{Transforming pathways: Transformative learning and migration}

This paper adds a new dimension to the idea of TL by introducing a framework that allows educators to support migrants in their attempt to increase their ability to weave contingent but coherent elements into a life story, to (re-)create an autobiography. Wildemeersch's (2017) differentiation between teleological and non-teleological dialogue offers additional insights. The former follows some kind of agenda and is supposed to arrive at a particular answer, whereas the latter is a form of open-ended conversation. The distinctive aspect between the two is, for Wildemeersch (ibid.), less the role and more the attitude of the educator. The risk one takes is not equally distributed within teleological dialogue, it rests solely on the learner putting her or his (self-)understanding at risk by engaging in critical reflection on one's assumptions. This is one of the problems coming with a dialogical approach, especially within a teleological perspective. I will argue later, that the educator who wants to foster TL should aspire to what I call a transformative conversation instead and learning to become a co-conversationalist, putting her or his (self-)understanding at risk through the means of a non-teleological approach.

In contrast to the instrumental view of learning within the context of migration, where immigrants are offered a particular vision of what citizens should look like, the skills and knowledge needed, TL offers a different possibility. TL, indeed offers something to migrants that is different from indoctrination, no short-hand way of becoming citizens, and reflects a different site of the migration studies. As a theory, TL has been around quite for some time and sheds light on positive and negative learning outcomes (Mezirow \& Taylor, 2009).

According to Mezirow and Taylor, TL is 'an approach to teaching based on promoting change, where educators challenge learners to critically question and assess the integrity of their deeply held assumptions about how they relate to the world around them' (2009, p. xi). It aims at transforming assumptive clusters, which form a meaning perspective or frame of reference. Mezirow (1991) describes this as a perspective 
transformation, where the learner (1) gains critical awareness of taken-for-granted assumptions and how they have shaped and limited one's way of being in the world, and (2) transforms them to make them more open, integrative, discriminating and inclusive. Concerned with both the private and public sphere, TL's main goal is to enable adults to come to an understanding about their own ideas, meanings and values, instead of those they have inherited and uncritically assimilated from others (ibid.). Within the private sphere, TL wants to support adults to liberate themselves from self-imposed limits on how one should live. Within the public sphere, TL aims at supporting adults to become socially responsible decision makers, actively engaging in questions about how to live together, and being able to transform society towards a more habitable place.

Not all learning in adulthood is necessarily transformative, for example learning a new language, gaining knowledge about culture and society or building on existing knowledge (Mezirow, 2012). Transformative dimensions of adult learning in the context of migration involve transforming points of view and/or habits of mind. Learning is only transformative when there is a difference in how one knows, not just in what one knows (Kegan, 2000). If one is not able to solve a problem within her or his current (self-)understanding, when formerly unproblematic notions and (meaning) perspectives are questioned, and 'the coherence-producing mechanism of our minds is interrupted [and] [w]e are no longer able to interpret the situation based on our previous experiences' (Mälkki, 2019, p. 64), we need to learn transformatively. This interruption is what Mezirow $(1978,1991,2012)$ identifies as disorienting dilemma - an essential first step towards TL.

TL is concerned with personal change and social action within the private and public spheres. '[T]he site of change - as well as agency - is envisaged primarily in terms of the transformation of the inner mental landscape of an individual learner which may, or may not, have broader social consequences' (Finnegan, 2019, p. 48). Finnegan (2019) argues that even though Mezirow's theory of TL is concerned with the individual, it is not individualistic since it emphasises intersubjective learning through discourse (Mezirow, 1991). Others 'serve as critical mirrors who highlight our assumptions for us and reflect them back to us in unfamiliar, surprising, and disturbing ways' (Brookfield, 2000, p. 146).

Why is TL a useful lens for understanding migration? It allows us to reflect on societies being transformed in the aftermath of processes of migration. And, on an individual level, it offers a distinctive perspective to understand migratory experiences in the light of transformation. I will first review the connections that have been drawn between TL and migration. Proceeding from there; I will highlight understudied questions and findings that enhanced TL. It is not surprising that TL has been important in the context of migration (e.g. Morrice, 2012, 2014, Webb, 2015). Scholars used TL mainly as a lens to understand the experience of migration (e.g. Magro, 2009, Magro \& Polyzoi, 2009), mainly by referring to the works of Mezirow (e.g. 1991, 2000) as the architect of TL theory (see e.g. Jurkova \& Guo, 2018, Magro \& Polyzoi, 2009, Margaroni \& Magos, 2018, Webb 2017). They have engaged in the idea of learning a new frame of reference (Margaroni \& Magos, 2018) and explored disorienting dilemmas that are inherent in migrants' experiences, trying to cope with an overwhelming loss, migration and transitions (e.g. Magro, 2007, 2009, Magro \& Polyzoi, 2009, Margaroni \& Magos, 2018, Morrice, 2013). Learning in the context of migration is potentially transformative and intense: 'The process of migration disrupts the inherited frames of reference and the accumulated biographical repertoire of knowledge and understanding' (Morrice, 2013, p. 252). The need migrants are facing to reshape their lives and modify identities in the aftermath of migration has been explored (e.g. Magro, 2009, Morrice, 2014), as well as engaging in critical reflection (Magro \& Polyzoi, 2009), or premise reflection that may 
lead to perspective transformation (e.g. Magro \& Polyzoi, 2009, Margaroni \& Magos, 2018, Morrice, 2014). Most researchers have identified similar phases of transformation as Mezirow suggests (e.g. Jurkova \& Guo, 2018, King, 1999, Magro \& Polyzoi, 2009, Morrice, 2013) and emphasized cross-cultural/intercultural awareness as a potential outcome of the migratory experience (e.g. King, 1999, Margaroni \& Magos, 2018, Taylor, 1994, Webb, 2017).

Understudied questions are, (despite the interest) the role of the transformative educator as a co-learner (e.g. Fursova, 2013, Magro, 2007), the interactions that lead to an increase in self-understanding (Jurkova \& Guo, 2018), and the need to explore alternative routes to transformation (Magro \& Polyzoi, 2009). Jurkova and Guo (2018) explicitly refer to Mezirow's Habermasian inspired validity claims and the need for a dialogue (not discourse as Mezirow suggests, e.g. 1991) that makes space for exploring new understandings of oneself and others. Margaroni and Magos describe the relationship between TL theory and migratory experiences at least to some extent as 'terra incognita' (2018, p. 207).

New insights for TL theory about what might constitute a transformative conversation with migrants, have emerged over the years. Proceeding from Fursova's (2013) work, we can identify distinctive aspects that are helpful in promoting TL in the context of migration, such as a format that (1) allows participants to learn from each other (about different (self-)understandings) and (2) helps them to identify and articulate skills and strengths in an appreciative environment. This leads to an increase in self-esteem and confidence, whereas learners felt patronised, when their resources skills were not acknowledged. We also learn from Fursova (2013) that women face both greater risks and benefits, renegotiating (traditional) stereotypes and roles. They have to carefully balance between renegotiation and a state of at least a temporary 'not-knowing' (Eschenbacher, \& Fleming, 2020) in order not to be alienated from their traditional sources of support.

Another interesting finding suggests that when migrants tried to revise their expectations to fit in, they developed different selves, a public and a private self, in which the former had been transformed to meet the new expectations whereas the latter remains hidden (Webb, 2017). Morrice's (e.g. 2013) research reveals a different, darker side of TL that connects somewhat with Webb's (2017) findings, suggesting that in the process of learning transformatively, adults have 'to unlearn and let go of much of who and what they were (....) It also involved learning to live with loss of professional identity and the social status and respect that accompanied their premigration identity' (Morrice, 2013, p. 266). We learn from her, that this process of transformation was coupled with an ontological process 'where individuals have to adjust their sense of who they are and what they can be in the world' (ibid., p. 267).

Reflecting on these insights, there is a need for educators who want to engage in what I call transformative conversation to pay attention to (1) the kind of format and conditions that enable or limit empowering ways to develop a coherent selfunderstanding; one that allows one to (2) reconcile different, even conflicting aspects of identity; and supports (3) securing a space where learners can explore different possibilities. This can be done by inventing and re-describing their self-understandings in ways that do justice to pre-migration and post-migration parts of identity, allowing them to navigate identity and belonging, and ultimately to redeem their past by investing painful experiences in a promising future. The question left to answer would be: What kind of conversation can adult educators offer? In what way should it be different to what we are already offering, and what would that mean in practice? What would a transformative conversation look like? 


\section{From transformative learning to transformative conversations: Rorty in dialogue with transformation theory}

Perspective transformation is an 'epiphanic, or apocalyptic, cognitive event - a shift in the tectonic plates of one's assumptive clusters' (Brookfield, 2000, p. 139). Learning transformatively is not 'a continuously joyful exercise in creative self-actualization' (Brookfield, 1990, p. 179) and there is often more to transformation than psychological change (Brookfield, 2000, Mezirow, 1991). The individualism of TL theory can be critiqued as migration education is where the public breaks into private lives. This paper supports a view of migrants learning transformatively within the private sphere. Instead of going beyond individualistic models, it is concerned with providing a theoretical framework that supports educators - in theory and practice - working to promote transformative conversations within groups, while also making space for private quests for meaning.

TL has always been concerned with assisting learners in their struggle with ambiguity and plurality. A Habermasian notion of rational discourse (Habermas, 1971, $1984,1987)$ is located at the centre of the theory. By engaging in an argumentative exchange, learners are supposed to transform their assumptive clusters (e.g. Mezirow, 1991, 2012). In reflecting this idea against the background of migratory experiences, the question arises whether deep personal processes of transformation, one's attempt to rebuild a shattered life and identity, are truly initiated or catalysed by exchanging arguments. Fursova (2013) criticizes Mezirow's notion of TL, as her findings suggest that learning transformatively from the perspective of migrants is not as rational as suggested.

In the search for a different format, one that is less limited to rational means, we shift the focus from exchanging arguments within discourse to the concept of conversation. The different aims of TL theory, personal and social change (Dirkx, 1998), need different practical educational formats. Habermas and his notion of discourse belong to the public, not to the private sphere (Rorty, 1989). An educational format of exchanging arguments is suitable for the public sphere, where participants are engaging in a debate about how they should live their lives. A format that needs - at least to some extent - consensus and solidarity, although we have learned from Wildemeersch (2017) how useful the element of dissensus can be in conversation - within the public sphere - especially with regard to the context of citizenship education and migration. What is still missing within TL theory is an educational format, a transformative conversation, that makes space for the question of how should $I$ live my life, where no consensus is necessary.

Adult educators wanting to support migrants in coping with their experience of a shattered self-understanding, need to be able to create a safe space. Reflective or rational discourse - as Mezirow suggests in order to promote transforming one's formerly unproblematic notions of identity, life, safety, etc. - might not be the most adequate format here. The coercive power of the better argument and a (tentative) consensus on how to deal with migratory grief, and experiences of loss and alienation seem to be out of place in this case. There is no need to arrive at a consensus on how one should deal with one's migratory experience, as there is no right way to do this. Of course, there is a need for a public discourse on how we want to live our lives together in the light of migration, how we can foster solidarity and democratic learning processes. But there is still a need for expanding TL theory by exploring new kinds of non-teleological dialogues, supporting migrants to transform their experiences into a learning opportunity with potentially positive outcomes.

Proceeding from Rorty's (1989) distinction between private and public vocabularies, we can add a useful dimension to TL theory: 'The vocabulary of self-creation is necessarily 
private, unshared, unsuited to argument. The vocabulary of justice is necessarily public and shared, a medium for argumentative exchange' (Rorty, 1989, p. xiv). By placing Habermas' notion of discourse at the heart of TL, the theory falls short. It lacks a form of dialogue that is suitable for the private quest for meaning without being obliged to exchange arguments and to look for the non-coercive force of the better argument in order to defend one's self-understanding. By bringing TL theory into conversation with Rorty's ideas, the theory addresses the gap of fostering TL, without promoting the idea of exchanging arguments, in a quest for arriving at a new self-understanding and coping with migratory grief.

Migratory experiences can be traumatic, as the ones described in Sea Prayer. Leaving one's home, being abruptly and violently disrupted from everything that has been meaningful can be, and most often is, traumatic. There is mourning to be done in order to cope and ultimately to grow and develop - as mentioned earlier - and that certainly cannot be done within rational discourse.

What kind of format would be better suited? We have already learnt from Rorty (1989) that the vocabulary of self-creation is private and unsuited for argument. What does he mean by vocabulary?

All human beings carry about a set of words which they employ to justify their actions, their beliefs, and their lives. These are the words in which we formulate (...) our deepest self-doubts and our highest hopes. They are the words in which we tell, sometimes prospectively and sometimes retrospectively, the story of our lives. (Rorty, 1989, p. 73)

The vocabulary one employs is close to Mezirow's notion of a frame of reference as they guide our actions and provide us with clarity and certainty (Eschenbacher, 2019). They are the words in which we express our deepest self-doubts and highest hopes; in the context of migration, they include the migrants' attempt to survive and realize their dreams. As the words used to story or re-story lives - retrospectively and prospectively they connect pre-migratory and post-migratory experiences. How can we support migrants in transforming their vocabularies? Through instrumental, informative learning that takes place, like learning a new language or acquiring cultural knowledge, the learner extends the vocabulary. It is Rorty's idea of irony that stresses the contingent nature of the way we construct and reconstruct our being in the world by employing one vocabulary among others. We are free to create new vocabularies by transforming our guiding assumptions, by employing new, formerly unknown words. Rorty's (1989) ironist idea is inviting us to explore different vocabularies as proposals regarding how one might live (Bernstein, 2016) instead of discussing arguments in order to see what we can all agree on to be the right way to live. Irony, according to Rorty (1989) is the opposite of common sense: When we take ideas, inherited final vocabularies or frames of reference for granted, we act commonsensical. Rorty 'wants to liberate us from the dead weight of past vocabularies and open up space for the imaginative creation of new vocabularies' (Bernstein, 2016, p. 52).

The close connection between Mezirow's idea of a frame of reference and Rorty's notion of vocabulary are coupled with the idea of transformation, whereas the former is about perspective transformation through premise reflection (Mezirow, 1991) and the latter is about redescribing oneself and one's being in the world (Rorty, 1989). To free ourselves from limits that are either self-imposed or learnt informally (here through discourses employing certain prejudices), we need to enhance our

ability to appreciate the power of redescribing, the power of language to make new and different things possible and important — an appreciation that becomes possible only when 
one's aim becomes an expanding repertoire of alternative descriptions rather than The One

Right Description. (Rorty, 1989, p. 39-40)

Here, the difference between exchanging arguments through discourse and the idea of redescribing through conversation becomes apparent. When we decide not to engage in teleological dialogues to support migrants in their quest for meaning and selfunderstanding, by not looking for one right description, we open space for conversations about different, alternative vocabularies (self-understandings) and proposals of how one might live, and establish and rebuild a meaningful life that has been shattered. This reminds me of what a transformative conversation might look like.

We learn from Dirkx (2012) that TL can be conceptualized as self-formation, a self that is understood as active and agentic, 'acting on and often creating the worlds which it inhabits. It is a reflective, dialogical, expressive, and deeply emotional and spiritual self that constructs and re-constructs itself through experiences of learning' (Dirkx, 1998, p. 10). This understanding of self is close to Rorty's understanding, as we learn from Bernstein (2016): 'we are not merely passive recipients of these vocabularies; we are free to create new vocabularies. And it is this creative freedom that Rorty wants to foster' ( $p$. 47).

Bringing Rorty in conversation with TL broadens what is at the heart of the theory, the idea that one is not trapped by one way of looking at or being in this world, but free to create new vocabularies and transform assumptive clusters (Eschenbacher, 2019), what I refer to as transformative conversation. Rorty's hope for transformation is reflected throughout his writings and is shared in the attempt of the transformative educator to support learners to cope with (traumatic) migratory experiences, to ultimately transform and rise to the occasion in the midst of adversity. So that 'what the past tried to do to her she will succeed in doing to the past: to make the past itself, including those very causal processes which blindly impressed all her own behavings, bear her impress' (Rorty, 1989, p. 29). Transformative conversation is dedicated to this kind of engagement with one's past.

\section{Arcilla's concept of edifying conversation as a basis for transformative conversations}

The idea of transformative conversation rests on Arcilla's concept of edifying conversation, understanding the edifying dimension as central for TL. What is meant by the term edification? What is its relationship to a vocabulary? Proceeding from Arcilla (1995), Rorty understands the term edification as autobiography: 'As we edify ourselves in response to events that befall us (...) we develop our ability to weave contingent but consistent stories of the course of our own lives' (Arcilla, 1995, p. 100). In developing the philosophical concept of edifying conversation and translating it into the context of learning, Arcilla defines conversational edification as 'the power to converse reasonably with others for the purpose of edifying oneself' (ibid., p. 105). The idea of edification, of developing our ability to form a coherent, but contingent story of ourselves, is central to the notion of transformative conversation.

It rests on the work of Oakeshott $(1989$, p. 41$)$ : 'The invitation of liberal learning... [is] the invitation to disentangle oneself, for a time, from the urgencies of the here and now and to listen to the conversation in which human beings forever seek to understand themselves'. By drawing on Oakeshott and his notion of liberal learning, Arcilla extrapolates several distinctive features of what he frames as a liberal education. Arcilla's (1995) reading of Oakeshott allows us to consider several crucial points: He highlights 
(1) Oakeshott's concern with learning (and not with teaching), (2) its invitational character, where the learner is free to accept or reject listening to the conversation. This invitation comes with (3) the idea of disentangling for some time, (4) to listen, when (5) human beings are trying to understand themselves (more fully). Arcilla (1995) broadens Oakeshott's invitation not only to listen but to join the conversation.

The invitation to disentangle oneself for some time might sound problematic in the context of migrants facing multiple challenges. How can one disentangle facing the urgencies of today (and yesterday)? We learn from (Vinciguerra, 2017, p. 359) that ' $[\mathrm{t}] \mathrm{he}$ crisis imposes a rest not from life but in life'. So, what motivates adults, or in our case migrants, to learn? And how should this kind of learning be conceptualized? What is the learner's role? What is the educator's role?

\begin{abstract}
What motivates your efforts to learn is the desire for self-knowledge. Yet what if the others to whom you turn have no way of directly revealing you to yourself; what if they are equally searching for themselves? If there is any hope for liberal learning in such a situation, then it must lie in the power of the conversation as a whole, beyond the control of any single participant. (Arcilla, 1995, p. 6)
\end{abstract}

How can we conceptualize the educator's role, assuming that she or he is part of the transformative conversation but not more powerful than anyone else? This transformative education is inspired by Rorty's (1989) idea of redescription and Arcilla's (1991) concept of edifying conversation. What do we have to keep in mind if we want to engage in a form of radical questioning, attempting to liberate us from the dead weight of past vocabularies or self-imposed limits? This kind of questioning can be terrifying and dangerous (Bernstein, 2016): terrifiying because we might encounter what Brookfield called a tectonic shift in one's assumptive clusters (Brookfield, 2000, p. 139), challenging us to giving up what used to orient us; dangerous, because we might feel lost in some sense, 'it seems to leave us with nothing' (Bernstein, 2016 p. 121).

We have learnt from Fursova (2013) that some aspects are more helpful than others when educating from a transformative perspective with migrants. The kind of reflection that is a prerequisite to engage in TL was more likely to take place through an educational format that promoted a dialogical and meaningful engagement with diversity, where participants were able to share their experiences, ideas and emotions, in a 'constructive engagement with otherness' (Daloz, 2000, p. 110). How does this idea of constructive engagement with others and otherness translate into practice? What is the role of the other? Following Arcilla participants are in need of

each other to help them rediscover a sense of self-direction which they must nevertheless claim for themselves. Hence they have recourse to conversation, to an exploratory, associative, open-ended, tolerant exchange of intimations free from the demand that it issue in conclusions binding on all. $(1995$, p. 7$)$

\title{
Towards a transformative and edifying conversation
}

Knowing more about the role of the other educator, the question remains unanswered from the very beginning of this paper: What attitude - from the perspective of the transformative educator - is more likely to foster TL working with migrants? We know from Jurkova and Guo that both educators and learners should engage as 'collaborators of knowledge and co-learners instead of being labelled as experts and non-experts or divided by the power and authority' (2018, p. 184). It is essential to create an environment 
acknowledging 'the uniqueness of one's identity and cultural background' (Webb, 2017, p. 174). The role of the educator may be one of a co-learner (Fursova, 2013, Magro, 2009) being not afraid to put one's own self-understanding at stake, and participate as what Arcilla calls 'fellow conversationalists engaged in questioning themselves before taking things for granted, in order to receive their being at a loss as a present' $(1995$, p. 2).

Following Wildemeersch, there might be a space for such a transformative conversation:

The participants want to learn about the place where they have eventually arrived, about the language and the culture and about their chances of getting integrated. Yet they also want to tell about the places they come from, about their own languages and cultures, and about their hopes of starting a new life. Such educative moments for asylum seekers are not one-directional actions, whereby the 'master' teaches how the participants are expected to behave, what the values and norms of the host community are, and how they are supposed to accommodate themselves to these. It is a multi-directional experience creating opportunities for both participants and facilitators to articulate their own, unique voices. (2017, p. 124)

There is a need for opening a conversation where one can engage in reflecting on migratory experiences to edify and transform. The ultimate goal of adult education is to empower, that is no different in the context of working with migrants (King, 1999). This comes with the necessity to create some kind of safe haven where participants can generate a feeling of inclusion and appreciation (Magro, 2007) in their attempt to rethink themselves and their possibilities of being (Morrice, 2014) and to find a way in addressing the differences between their public and private selves (Webb, 2017).

We have learnt from Magro (2009) that navigating one's identity and belonging most often is a rather precarious path for migrants, living and experiencing a fragile, vulnerable life (Magro \& Polyzoi, 2009). The migratory experience of interruption of one's takenfor-granted way of being and living in the world that comes with a disruption of inherited frames of reference, 'have led them to realize that they have, to some extent, lost their way in the world, or that the world affords them no way to what they love' (Arcilla, 1995, p. 7). Instead, most often they have to reconcile the 'conflict between the ideal or imagined identities that they hoped to create, and the reality of an identity that restricts' (Morrice, 2013, p. 261). In order to come to a new understanding of oneself and one's being in the world, engaging in transformative conversation might present a possible solution to the problematic, darker side of TL (Morrice, 2013, 2014) to edify and rebuild a new, empowered sense of self-understanding (Magro \& Polyzoi, 2009).

When 'the various self-conceptions you take for granted do not form a coherent whole' (Arcilla, 1995, p. 6), learners need a space where they can quest after a deeper, more coherent understanding of themselves (ibid.). What we have learnt from research on migration (and TL), is that there is a need to restory, to arrive at a new, transformed self-understanding (Morrice, 2014, Tarusarira, 2017) especially when life stories do not form a coherent whole anymore. This is where an edifying conversation needs to evolve as a transformative conversation. At times, migrants have to manage dual identities (Webb, 2017), facing a hybridity of their self-understandings (Webb \& Lahiri-Roy, 2019). Experiences of migration have to be understood against the (auto-)biographical background of migrants (Morrice, 2014); the vocabularies they employ to story their lives, retrospectively and prospectively, otherwise we are unable to understand their hopes, aspirations, expectations, doubts, and fears and the changes in their selfunderstandings (King, 1999). Engaging in what has been introduced here, the concept of transformative conversation, is one possibility to foster the kind of edification and 
reconciliation (Tarusarira, 2017) migrants need with themselves, to find a way to redeem their pasts and generate possible answers and explore options to the question that is central to the concept of edifying and transformative conversation: 'Will you be able to recast what life throws, and has thrown, at you in your own terms?' (Arcilla, 1995, p. 99). This ability to recast in one's own terms and the need for reconciliation is central to coping with traumatic experiences.

Arcilla's (1995) theory of edifying conversation is better suited than Habermas' idea of discourse - in the context of TL - to give guidance to anyone who wants to help others to question taken-for-granted beliefs that are no longer viable. The Rortyan (1989) ironist notion offers a multiculturalist grounding for the idea of edifying conversation. However useful here, Rorty's ideas are not totally unproblematic and need to be carefully translated into an educational context (see Arcilla, 1995, Bernstein, 2016, Janik, 1989).

Rorty understands an ironist as someone who 'affirms both her or his solidarity with a culture and her or his project to distinguish herself or himself individually, and who attempts to prevent these commitments form disrupting each other by compromising between them in practice' (Arcilla, 1995, p. 22). Following Arcilla, Rorty's notion of liberal education is 'explicitly and necessarily multiculturalist' (ibid., p. 22). And so is his concept for edifying conversation: 'The longing in liberal learning is, rather, that for an opportunity where you can use various cultural resources for conversational edification to struggle heroically with a problem in your culture' (ibid.). The need to converse cultural differences in order to understand them and oneself in the context of adult education and migration (Morrice, 2013), sets the stage for engaging in edifying and transforming ourselves through conversation, facing 'the cultural stranger, whose alternative terms of self-understanding expose the self-understanding of both to questionableness. (....) Behind diversity, a common sense of strangeness' (Arcilla, 1995, p. 151) creates a bond between all who are engaged in conversation.

\section{Final thoughts}

'The need to develop, to learn and to practice the art of living with strangers and their difference permanently and daily is inescapable' (Bauman \& Mazzeo, 2012, p. 3). Therefore, we as adult educators need to explore ways that allow us to model this art of living. One way to do this is by engaging in non-teleological dialogue and a pedagogy of interruption (Wildemeersch, 2017) within the public sphere. But, there is also another way of engaging within the private sphere through edifying conversations. Both ways allow us as educators to engage with plurality meaningfully. It opens a space for what I am calling transformative conversations that makes room for one's private quest for meaning by turning that quest into an opportunity for change and transformation.

In searching for a possible attitude for the transformative educator working with migrants, the concepts of edifying and transformative conversation has been introduced and explored. Concepts that invite the educator to transform her or his self-understanding by becoming a fellow conversationalist, one who has an opportunity to learn deeply from others, who have experienced that their formerly unquestioned way of being and living in this world is contingent, one way to live among others. In these conversations one may learn to listen to the highest hopes and deepest fears, the 'Sea Prayers and discover other's ways of achieving a sense of self-direction while having lost one's way in the world. It is through edifying ourselves that we learn that '[o]ne is not trapped by one way of looking at the world or being in the world that is forced on us, but we are free to create new vocabularies and to transform our guiding assumptions' (Eschenbacher, 2019, p. 258). 


\section{Acknowledgment}

I am deeply grateful for the edifying - and for me transformative - conversations I have had with René V. Arcilla about the ideas of transformation and being an educator. I'm indebted to Ted Fleming, who helped me find a language for what I am trying to say.

\section{References}

Arcilla, R. V. (1995). For the love of perfection: Richard Rorty and liberal education. New York: Routledge.

Bauman, Z., \& Mazzeo, R. (2012). On education: Conversations with Riccardo Mazzeo. Oxford: Wiley.

Bernstein, R. J. (2016). Ironic life. Cambridge: Polity Press.

Biesta, G. (2012). Becoming public: Public pedagogy, citizenship and the public sphere. Social and Cultural Geography, 13, 683-697.

Brookfield, S. D. (1990). Using critical incidents to explore learners' assumptions. In J. Mezirow (Ed.), Fostering critical reflection in adulthood: A guide to transformative and emancipatory learning (pp. 177-193). San Francisco: Jossey-Bass.

Brookfield, S. D. (2000). Transformative learning as ideology critique. In J. Mezirow (Ed.), Learning as transformation: Critical perspectives on a theory in progress (pp. 125-148). San Francisco: JosseyBass.

Daloz, L. A. P. (2000). Transformative learning for the common good. In J. Mezirow (Ed.), Learning as transformation: Critical perspectives on a theory in progress (pp. 103-123). San Francisco: JosseyBass.

Dirkx, J. M. (1998). Transformative learning theory in the practice of adult education: An overview. Journal of Lifelong Learning, 7, 1-14.

Dirkx, J. M. (2012). Self-formation and transformative learning: A response to "Calling transformative learning into question: Some mutinous thoughts," by Michael Newman. Adult Education Quarterly, 62(4), 399-405.

Eschenbacher S. (2019). Drawing lines and crossing borders: Transformation theory and Richard Rorty's philosophy. Journal of Transformative Education, 17(3), 251-268.

Eschenbacher, S., \& Fleming, T. (2020). Transformative dimensions of lifelong learning: Mezirow, Rorty and Covid-19. International Review of Education: Journal of Lifelong Learning, 66(5-6).

Finnegan, F. (2019). 'Freedom is a very fine thing': Individual and collective forms of emancipation in transformative learning. In T. Fleming, A. Kokkos, \& F. Finnegan (Eds.), European perspectives on transformation theory (pp. 43-57). Cham: Palgrave Macmillan.

Fursova, J. (2013). A journey of her own: A critical analysis of learning experiences among immigrant women. RCIS Working Paper, 33, 1-18.

Gibb, T. (2015). Regimes of language skill and competency assessment in an age of migration: the in/visibility of social relations and practices. Studies in Continuing Education, 37(3), 251-266.

Habermas, J. (1971). Knowledge and human interest. Boston: Beacon Press.

Habermas, J. (1984). The theory of communicative action. Reason and the rationalization of society. Vol. 1. Boston: Beacon Press.

Habermas, J. (1987). The theory of communicative action. Lifeworld and system. A critique of functionalist reason. Vol. 2. Boston: Beacon Press.

Hosseini, K. (2018). Sea prayer. London: Bloomsbury.

Janik, A. (1989). On edification and cultural conversation: A critique of Rorty. In A. Janik (Ed.), Style, Politics and the Future of Philosophy. Boston Studies in the Philosophy of Science, 114 (pp. 80-92). Dordrecht: Springer.

Jurkova, S., \& Guo, S. (2018). Connecting transculturalism with transformative learning: Toward a new horizon of adult education. The Alberta Journal of Educational Research, 64(2), 173-187. 
Kegan, R. (2000). What "form" transforms? A constructive-developmental approach to transformative learning. In J. Mezirow (Ed.), Learning as transformation: Critical perspectives on a theory in progress (pp. 35-69). San Francisco: Jossey-Bass.

King, K. P. (1999). Changing languages, cultures, and self: The adult ESL experience of perspective transformation. $\quad$ Retrieved July $\quad 15, \quad 2020, \quad$ from https://newprairiepress.org/cgi/viewcontent.cgi?article=2836\&context=aerc

Kurantowicz, E., Salling Olesen, H., \& Wildemeersch, D. (2014). Editorial: a human being is a human being is a human being is a human being - the issue of migration in Europe and the responses of adult education. European Journal for Research on the Education and Learning of Adults, 5(2), 144-147.

Magro, K. (2007). Exploring the needs and challenges of adults from war affected backgrounds. Retrieved July 15, 2020, from https://newprairiepress.org/cgi/viewcontent.cgi?referer=https://www.google.com/\&httpsredir=1\&artic $\mathrm{le}=2576 \&$ context $=$ aerc

Magro, K. (2009). Negotiating new cultural and social terrain: Working toward transformative learning approaches in immigration research. Journal of the Manitoba Educational Research Network 5(3), 620.

Magro, K., \& Polyzoi, E. (2009). Geographical and psychological terrains of adults from war-affected backgrounds. Journal of Transformative Education, 7(1), 85-106.

Margaroni, M., \& Magos, K. (2018). Refugee experience and transformative learning. Global Education Review, 5(4), 194-210.

Mezirow, J. (1978). Perspective transformation. Adult Education Quarterly, 28(2), 100-110.

Mezirow, J. (1991). Transformative dimensions of adult learning. San Francisco: Jossey-Bass.

Mezirow, J. (2000). Learning to think like an adult: Core concepts of transformation theory. In J. Mezirow (Ed.), Learning as transformation: Critical perspectives on a theory in progress (pp. 3-33). San Francisco: Jossey-Bass.

Mezirow, J. (2012). Learning to think like an adult: Core concepts of transformation theory. In E. W. Taylor \& P. Cranton (Eds.), The handbook of transformative learning: Theory, research, and practice (pp. 7395). San Francisco: Jossey-Bass.

Mezirow, J., \& Taylor, E. W. (2009). Preface. In J. Mezirow \& E. W. Taylor (Eds.), Transformative learning in practice: Insights from community, workplace, and higher education (xi-xiv). San Francisco: Jossey-Bass.

Morrice, L. (2013). Learning and refugees: Recognizing the darker side of transformative learning. Adult Education Quarterly, 63(3), 251-271.

Morrice, L. (2014). The learning migration nexus: towards a conceptual understanding. European Journal for Research on the Education and Learning of Adults, 5(2), 149-159.

Morrice, L. (2019). Abyssal lines and cartographies of exclusion in migration and education: towards a reimagining. International Journal of Lifelong Education, 38(1), 20-33.

Mälkki, K. (2019). Coming to grips with edge-emotions: The gateway to critical reflection and transformative learning. In T. Fleming, A. Kokkos, \& F. Finnegan (Eds.), European perspectives on transformation theory (pp. 59-73). Cham: Palgrave Macmillan.

Oakeshott, M. (1989). A place of learning. In T. Fuller (Ed.), The voice of liberal learning: Michael Oakeshott on education (pp. 17-42). New Haven: Yale University Press.

Rorty, R. (1989). Contingency, irony, and solidarity. Cambridge: Cambridge University Press.

Tarusarira, J. (2017). Development education and the psychosocial dynamics of migration. Policy \& Practice: A Development Education Review, 24, 88-103.

Taylor, E. W. (1994). Intercultural competency: A transformative learning process. Adult Education Quarterly, 44(3), 154-174.

Vinciguerra, M. (2017). Narrating migration. In A. Laros, T. Fuhr, \& E. W. Taylor (Eds.), Transformative learning meets Bildung: An international exchange (pp. 353-362). Rotterdam: Sense Publishers.

Webb, S. (2015). Learning to be through migration: Transformation learning and the role of learning communities. International Journal of Continuing Education and Lifelong Learning, 8, 62-84.

Webb, S. (2017). Learning to manage the self and the hidden injuries of migration. Studies in the Education of Adults, 49(2), 157-176. 
Webb, S., Hodge, S., Holford, J., Milana, M., \& Waller, R. (2016). Refugee migration, lifelong education and forms of integration. International Journal of Lifelong Education, 35(3), 213-215.

Webb, S., \& Lahiri-Roy, R. (2019). Skilled migrants and negotiations: New identities, belonging, home and settlement. Journal of Intercultural Studies, 40(2), 190-205.

Wildemeersch, D. (2017). Opening spaces of conversation: Citizen education for newcomers as a democratic practice. International Journal of Lifelong Education, 36(1-2), 112-127. 